\title{
Prevalence of Traumatic Dental Injury in Arab Israeli Community
}

\author{
Abu-Hussein Muhamad ${ }^{1}$, Nezar Watted ${ }^{2}$, Azzaldeen Abdulgani $^{3}$, \\ Mai Abdulgani ${ }^{4}$ \\ ${ }^{1}$ University of Naples Federico II, Naples, Italy, Department of Pediatric Dentistry, University of Athens, \\ Greece \\ ${ }^{2}$ Triangle R\&D Center, Kafr Qara, Israel, Clinics and policlinics for Dental, Oral and Maxillofacial Diseases \\ of the Bavarian Julius-Maximilian-University, Wuerzburg, Germany \\ ${ }^{3}$ Department of Conservative Dentistry, Al-Quds University, Jerusalem, Palestine \\ ${ }^{4}$ Private dental practice, Nahf, Galilee,Israel
}

\begin{abstract}
Traumatic dental injury (TDI) in school children has become a serious dental public health problem in developing and developed countries. Worldwide research clearly shows that the prevalence of TDI is increasing.

Objective: The purpose of this study is to clinical compare without use radiograph film in comparing between groups of boys and girls which complain of traumatic fracture of anterior permanent teeth in enamel and dentine reigns with or with out Pulp rom records of patients aged 9-12years.

Design: A descriptive cross-sectional survey in Arab Israeli schoolchildren between 2003-2015.

Subjects: A sample of 4262 ,Arab Israeli schoolchildren (2344(55\%)) males and 1918(45\%)) females) aged 9-12years, were interviewed and examined between 2003-2015in different dental private clinics in Israel.

Results: Among the 4262 schoolchildren examined, 520(12,2\%) had experienced traumatic dental injuries (TDIs). Males had experienced a significantly higher prevalence of trauma 340(8\%) than females $180(4,2 \%)$.

Conclusion: Overall traumatised permanent incisors were found to occur fairly

frequently with males having experienced significantly more TDIs than females. Theprevalence of TDIs in Arab Israeli schoolchildren was 12,2\%; enamel fractures were the most frequently observed injury and falls were the leading cause of trauma.
\end{abstract}

Keywords: Permanent Teeth, School Children, Trauma,Arab Israeli(Arab48)

\section{Introduction}

Traumatic dental injuries (TDIs) are considered a public health problem due to their high prevalence rate, [1] extensive knowledge of their etiology, which allows the establishment of prevention strategies and the high costs of such injuries, such as the direct cost of treatment , indirect costs linked to missing days of work and school and the impact of dental trauma on quality of life.[1-3]

Anterior permanent teeth have esthetic and functional importance including significant effect on the individual facial profile. Facial trauma leads to fractured, displaced or lost teeth which can have significant negative functional, esthetic and psychological impact on children and adolescent [4].

The most common injuries to permanent teeth occur as a result of road traffic accidents (bicycle injury) followed by sports, falls and violence [2,3]. All sporting activities had risk of oro-facial injuries due to fall, collision and contact with hard surface [4]. Use of mouth guard which helps to distribute the force of impact and reduces the risk of severe injuries to the tooth [5].

The treatment strategy after injury to a permanent tooth is dictated by the concern for vitality of the pulp and periodontal ligament. In order to evaluate the extent of the injury and to correctly diagnose the injury to teeth, periodontal ligament and related structures, a systematic approach is needed [6]. Patients having spontaneous tooth ache, abnormal, response to pulp tests, or breakdown of peri radicular supportive structures, initiation of endodontic consultation and treatment is needed [6,7]. To stabilize a tooth following traumatic injury a splint may be necessary [8,9]. In some of the cases tooth need to be extracted and replaced with dental prosthesis.

In 1970 Andreasen studied the etiology and pathogenesis of traumatic injuries among 1,298 cases and showed that the causes of injuries can possibly reflect the differences in energy of impact. Cases with injuries due to fall during play, represents a trauma type of less impact energy than those cases with injuries due to fall from a bicycle or a motor vehicle and automobile accidents. Increase in energy of the trauma impact seems to be followed by an increase in bone injuries rather than tooth fractures. The investigator showed that the difference 
in the resiliency of the impacting object reflects the differences in injury pattern between fight injuries and a foreign body hitting the oral structure. The former represents a blunt or padded impact leading to periodontal ligament injuries, while the latter represents a hard unelastic impact that tends to cause tooth fracture rather than periodontal ligament injury. If the lip is hit first by trauma, it may possibly act as an impact absorber reducing the chance of fracture and increasing the risk of luxation.[8-11]

The frequency of trauma to the permanent dentition in school age children peaked in the age group 915 years and 11-15 year olds .[8] In general, males were affected almost twice as females in both the primary and permanent dentitions. Traumatic dental injury may vary in its severity from a simple enamel fracture, which is the most prevalent type to multiple types of trauma affecting both soft and hard tissue, and even it may reach to a complete avulsion of the tooth . Dental trauma may be classified into categories based on treatment protocols, these categories include: Enamel and crown fracture, dental luxation, dental extrusion and intrusion, dental concussion and subluxation, root fracture and dental avulsion . [11-14]

Numerous studies on the prevalence of traumatic dental injuries in children and adolescents have been reported worldwide with documented incidence rangingfrom 4-33\% depending on the sex, age and the study design selected . The purpose of this study is to clinical compare without use radiograph film in comparing between groups of boys and girls which complain of traumatic fracture of anterior permanent teeth in enamel and dentine reigns with or with out Pulp rom records of patients aged 9-12years, who sought treatment at the different dental privates clinics in Arab Israeli from January 2003 to December 2015 . exposure in ages rang between ( 9) to (12) years.

\section{Materials and Methods}

In this epidemiological study, a sample of (4262) 9-12 years old Arab Israeli schoolchildren. $2344(55 \%)$ males and $1918(45 \%)$ females were selected randomly by cluster stratified sampling method from urban intermediate schools from different geographical areas in Arab Israelian schoolchildren. Girl's;Boys ratio being 1:1.2.This study involve Clinical data of involve 520 healthy children, with traumatized permanent anterior teeth fracture in this children samples were diagnosis alone them in to private Dental Clinics in Arabs Israel during school time, were collected. with traumatized permanent anterior teeth fracture, who were treated in to differents privates Dental Clinics in Arabs Israel during school time between 2003-2015

Data scores: As seen in table number (1) the distribution of score according to finding in our samples under diagnoses.

\begin{tabular}{|l|l|l|}
\hline $\begin{array}{l}\text { Scores } \\
\text { degree }\end{array}$ & Score discretion & $\begin{array}{l}\text { Score } \\
\text { number }\end{array}$ \\
\hline 1 & No fracture of any tooth tusse & 0 \\
\hline 2 & Fracture within enamel area only & 1 \\
\hline 3 & Fracture within enamel and dentine area only without pulp exposed & 2 \\
\hline 4 & Fracture from enamel and dentine involve expose pulp area & 3 \\
\hline
\end{tabular}

Table.1; Samples scores distribution

\section{Inclusion criteria:}

$>$ Arab Israelian Schoolchildren aged 9-12 years old, willing to participate in the study.

$>$ Individuals those who were willing to participate in the study.

$>$ Individual's not undergone or undergoing orthodontic treatment

\section{Exclusion criteria:}

1) Schoolchildren with extensive caries in the anterior teeth.

2) Schoolchildren with dental anomalies in tooth structure such as amelogenesis imperfecta, dentinogenesis imperfecta, or enamel or dentin hypocalcification werenm excluded.

3) Discolored teeth other than for trauma (intrinsic discoloration).

4) Case sheets with incomplete or incorrect information were excluded.

Instruments and Supplies: The following instruments and supplies were used. Plane mirrors (No. 4) were used for examination together with dental probe (00). Millimeter graded vernier (No L11-975 double scale 0-12 cm x $1.0 \mathrm{~mm}$ - GRIFFIN) with a depth gauge (Annex 2) was used for measuring the over-jet and overbite, metric ruler was used for double check. Containers (one for sterilized and one for the used instruments and kidney dishes for cotton pellets which are used with tweezers to clean the labial surfaces of examined teeth from any debris. Concentrated sterilizing solution, disposable gloves and masks were used. An indelible pencil was used to mark the measurement needed on the tooth surface.

Data scores: As seen in table number (1) the distribution of score according to finding in our samples under diagnoses. Entering of data and analysis was done using SPSS. The prevalence of the examined variables 
was calculated for each gender, age group. The influence of gender and age was measured separately for the examined dental trauma variables using chi-square tests.

For all the previous tests a probability value was used, a level more than 0.05 was regarded as insignificant, a p-value equal to or less than 0.05 was considered as significant while values of less than 0.01 were considered highly significant.

Table 2: Distribution of Students by Age and Gender.

\begin{tabular}{|l|l|l|l|}
\hline Age in year & $\begin{array}{l}\text { Boys group samples } \\
\text { numbers } \\
\text { percentages }\end{array}$ & $\begin{array}{l}\text { Girls group samples umbers with } \\
\text { percentages }\end{array}$ & $\begin{array}{l}\text { Total groups sample numbers } \\
\text { with percentages }\end{array}$ \\
\hline 9 years old & $160(47.1 \%)$ & $60(33.3 \%)$ & $220(42.3 \%)$ \\
\hline 10 years old & $100(29.4 \%)$ & $30(16.7 \%)$ & $135(25 \%)$ \\
\hline 11 years old & $60(17.6 \%)$ & $50(27.8 \%)$ & $110(21.2 \%)$ \\
\hline 12 years old & $20(5.9 \%)$ & $40(22.2 \%)$ & $60(11.5 \%)$ \\
\hline Total & $340(100 \%)$ & $180(100 \%)$ & $520(100 \%)$ \\
\hline
\end{tabular}

\section{Result}

After the evaluation of the registry books a group of 4252 patients were accounted for in the 12 years elected time period. The dentoalveolar trauma group numbered 520 patients ( $12,2 \%$ of all patients $)$. Sex distribution was: 340 male patients (8\%) and 180 female patients $(4,2 \%)$, The age range from(9-12)years as shown in Table(1),Table(2) Show Distribution of Diagnosed fracture anterior permanent teeth according to age and Sex. Fig.1

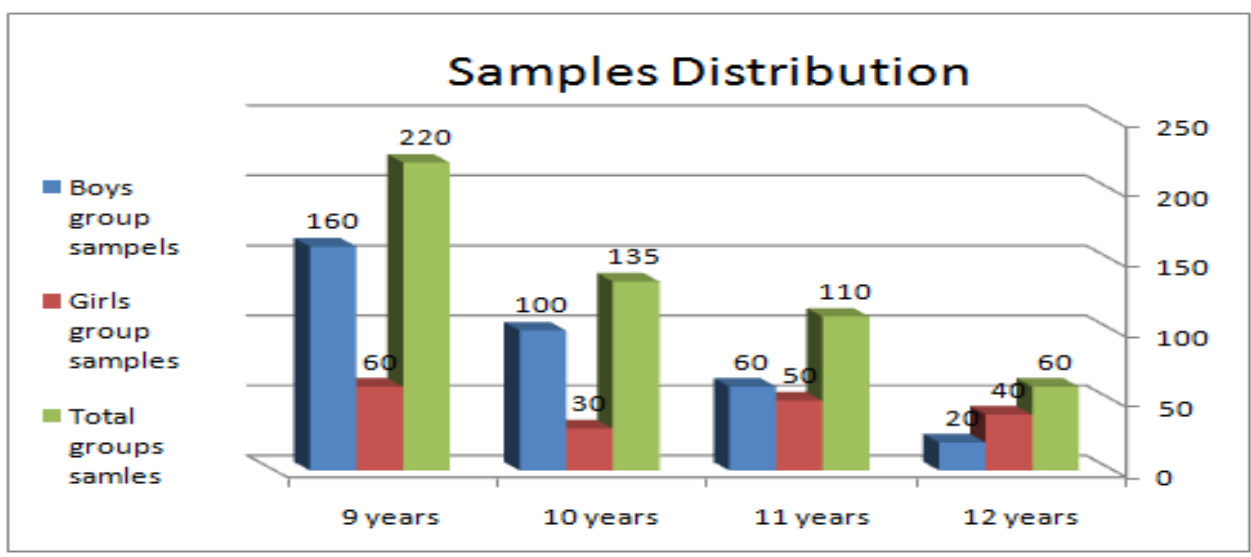

Fig.1: Distribution of Schoolchildren by age and gender.

The overall prevalence of TDI was found to be $12,2 \%$. The observed prevalence of dental trauma was higher in boys $(8 \%)$ than in girls $(4,2 \%)$. Table $(2,3,4)$,

Compared to the entire group of patients (Male and Female), there was no statistical significance between dentoalveolar trauma in male and female patients ( $p>0,05)$.

The gender distribution obtained statistical significace between males and females $(p<0.05)$ in both groups of patients Fig.1.

The final clinical data which obtain as seen in tables below and its diagrams the higher traumatic fractures are in the boys group sample as seen in table( 2,3$)$ and diagram number (1) more potency traumatic effect within age 8 years boy old and reduce in its potency with increase boys age. as seen in table $(2,4)$ and Figue number (1) the more potency traumatic effect in (age 12) yeas old girls group sample and we when compare between this two tables we see it more traumatic fracture happen with age 9years old but in low degree than that in boys, and this agree with Lihong Ge, etal in study .[15]When make compares within boy's samples we find the incidences of higher traumatic fractures( score 4) decrease with increase boys group sample' age 12 years old as seen in table $(3,4)$ and diagram (1). In comparison to girl group samples there is low degree of (score 4 )within( age 12)years old. Table $(3,4)$,

Table 3: Samples Scores Distribution in Boys Schoolchildren

\begin{tabular}{|l|l|l|l|l|l|l|l|}
\hline Age boy & Score 0 & Score 1 & Score 2 & Score 3 & Score 4 & Mean & SD \\
\hline 9 & 14 & 18 & 20 & 22 & 24 & 19.2 & 5.01996 \\
\hline 10 & 30 & 22 & 15 & 13 & 4 & 16.8 & 9.782638 \\
\hline
\end{tabular}




\begin{tabular}{|l|l|l|l|l|l|l|l|}
\hline 11 & 19 & 16 & 7 & 11 & 6 & 11.8 & 8.408329 \\
\hline 12 & 14 & 3 & 0 & 9 & 0 & 5.2 & 6.140033 \\
\hline
\end{tabular}

Fig.2; Samples scores distribution in boys Schoolchildren

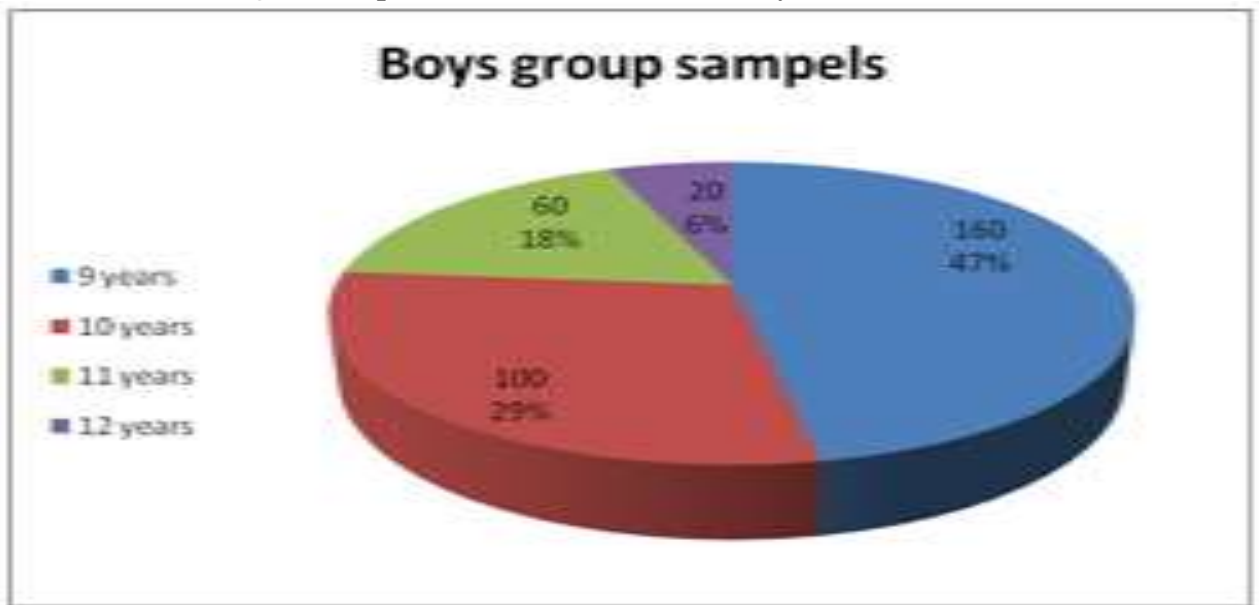

\section{Discussion}

This cross-sectional study identified a prevalence of $12.2 \%$ of TDI for permanent anterior teeth of 912-year-old Arabs Israel School children . The reported prevalence of TDIs in the Americans, Asians, and Brazilian adolescents ranged from $4.1 \%$ to $58.6 \%$ (4-8). Studies conducted among adolescent in India reported the prevalence rates ranging from $8.79 \%$ to $33.3 \%(3,11,12)$. The behavioral and cultural diversity may explain differences in findings between countries as well as within a country. Variation in sampling and diagnostic criteria between different studies may also explain differences in findings. Fig.1,2,3,4

Table 4; Samples Scores Distribution in Girls Schoolchildren

\begin{tabular}{|l|l|l|l|l|l|l|l|}
\hline Age girl & Score 0 & Score 1 & Score 2 & Score 3 & Score4 & Mean & SD \\
\hline 9 & 26 & 21 & 5 & 9 & 6 & 13.4 & 12.13672 \\
\hline 10 & 12 & 6 & 1 & 14 & 3 & 7 & 7 \\
\hline 11 & 8 & 3 & 8 & 13 & 6 & 8 & 5.958188 \\
\hline 12 & 3 & 11 & 8 & 8 & 10 & 8 & 4 \\
\hline
\end{tabular}

Fig.3; Samples scores distribution in Girls Schoolchildren

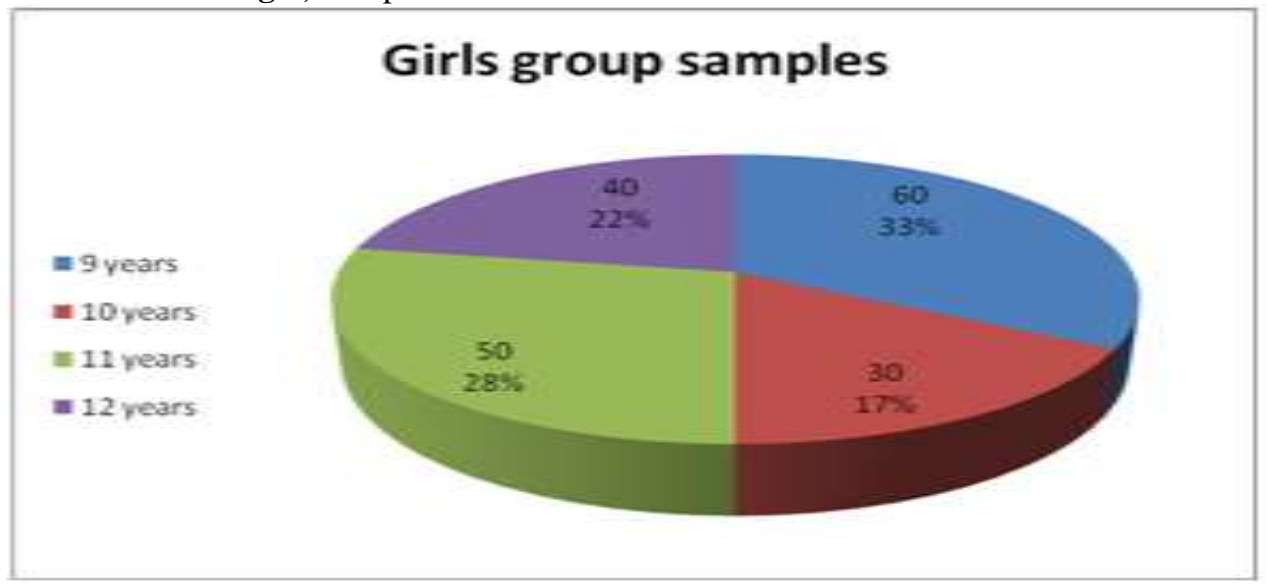

Studies have shown that males experienced traumatic dental injuries at least twice as oft en as females. Th e male:female ratio varies from 1.5:1.0 to 2.5:1.0 [13,17, 18]. Such ratio could be attributed to a greater participation of boys in contact sports, fights and car accidents. Also it could be related to the fact that girls are generally more mature in their behaviors than boys, who tend to be more energetic and active . However, some of the studies have shown a reduction in the gender ratio which might be due to increased sports activities among girls . [11-18] Altun et al. observed some association between gender and type of injury. Boys more often suffered from dental hard tissue and pulp injury than girls . [20]According to the results of the studies for a long time gender had been determined as one of the predisposing factors of dental injuries, while now traumatic dental injuries are more likely to be related to the activities and the environment . Fig.4 
Another well-known risk variable of traumatic dental injuries is age. Results of various studies showed the existence of the target groups. According to Lam et al. up to $92 \%$ of traumatic dental injuries occur before the age of 34 year. [23]Distinct age groups are determined and majority of injuries occur in the 0 to 4,5 to 9 and 10 to 14 years age groups. [17, 18]Discrepancies can be seen in the group of 6-14 year-olds in the rate of traumatic dental injuries within smaller subgroups. Altun et al. observed that injury rates were highest among children age 6 and ages 8-10 . [20]Eyuboglu et al. showed the highest frequency of traumatic dental injuries at the age $8-10$

[24]. While Diaz et al. observed that the highest rate of dental injuries in permanent dentition occurred in groups of 7-9- and 10-12- year-olds. [25]A study by Navabazam and Farahani identifi ed the 9-10 age range as the period of life when majority of the dental trauma occur .[26] In a study by Faus-Damia et al. the highest prevalence of traumatized children was at the age of 12.2 years old .[27]

Fig.4 Samples scores distribution in Girls and boys Schoolchildren

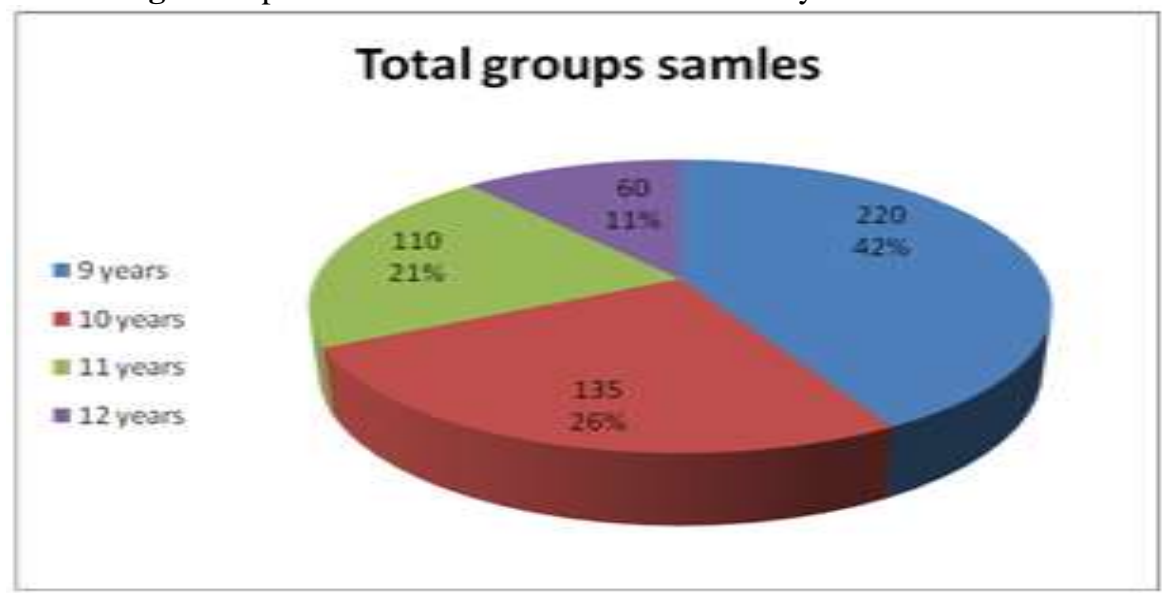

The prevalence of dental injuries increased with age. It rose from $42,3 \%$ at the age of 9years to $11,3 \%$ at 12 years. Significant differences were found betweenchildren 9 and 10 years old $(\mathrm{P}<0.001)$. There was a significant correlation between dental injuries and gender. Overall, boys were $8 \%$ times more likely than girls to experience dental injuries $(\mathrm{P}<0.001)$. Significant differences between boys and girls were found from 10 to 12 years old $(\mathrm{P}<0.05$; Table 2,3$)$.

This study showed that the prevalence of dental injuries increased with age from 9 to 12 years old, in agreement with other reports (30). Because most types of dental injuries were cumulative, the fact that the prevalence of dental injuries increased with age did not mean that the oldest were the most vulnerable. Granted that the comparison was made between different cohorts instead of between different ages for members of any one cohort, the differences between each consecutive age may serve as a rough estimate of the incidence of dental injuries.[28]

Among boys, dental trauma of permanent teeth was more frequent than in girls. This is probably contingent on the fact that boys are more active and they practise more aggressive sports or sports with a higher risk of accidents. Thus, sports such as judo, boxing, cycling, carting, athletics, hockey, and polo are more frequently practised by boys, whereas girls generally prefer dancing, ballet or swimming. Even while practising more dangerous sports, such as handball or basketball, girls appear more cautious than boys.

The prevalence of traumatic dental injuries among school children aged 9 - 12 years in Arab Israeli schoolchildren was $12.2 \%$. A total of 4262 school children had 520 school children fractured teeth. Differences in prevalence between boys and girls were not statistically significant, $55 \%$ in boys and $45 \%$ in girls.

Boys have more traumatic dental fractures ( $8 \%$ ) than girls (4,2\%). 17 According to Gassner, male to female ratio is $3.3: 1$. [29]

This difference in the gender distribution is supported by previous studies, and differs with Gutmann who reported equal involvement of males and females. The explanation for these findings could be the historically active role played by men in our society, while females are mostly confined to home. Moreover, girls are more mature in their behavior than boys, who tend to be more energetic and inclined towards vigorous outdoor activities. [30]

A study by Kumar A. et al. in India showed that the prevalence of dental traumas was $14.4 \%$ while in another district of South India it constituted 6\% and was rather low compared to other studies among 12-yearold schoolchildren .[31] Differences observed in prevalence of trauma could be related to the discrepancies of the performed sampling procedures. 
In a study of Chilian children and adolescents the group of 7 to 12 year olds had the highest frequency of traumatic dental injuries, i.e. $66.6 \%$. Bendo CB et al. showed the prevalence of traumatic dental injuries of $17.1 \%$ out of 1612 schoolchildren aged 11 to 14 years attending public and private schools .[32] A slightly higher percentage of dental traumas was reported in another study from Brazilian population, where the prevalence of traumatic injuries among adolescents aged 15 to 19 years old constituted $24.7 \%$.[33]

A Palestinian study conducted by Livny reported $17.7 \%$ prevalence of traumatic dental injuries. Enamel fractures and injuries involving dentine accounted for $41 \%$ and $42.5 \%$ of all dental injuries, respectively .[34]

Jainara Maria Soares Ferreira assessed the prevalence of dental trauma as compared to the prevalence of dental caries in children aged 3-59months. A cross-sectional study was carried out during the National Immunization Day for Polio in Recife, northeast Brazil. A total of 56,142 teeth were examined and the prevalence of dental trauma was $14.9 \%$. Dental fracture was the most prevalent injury observed in 516 teeth $(0.9 \%)$, followed by discoloration in $191(0.9 \%)$, intrusion in $12(0.02 \%)$ and extrusion in five $(0.008 \%)$. The most affected teeth were the upper central incisors and the prevalence of dental trauma altered significantly with age and family income. Dental trauma was most prevalent from 2 to 5 years of age. The prevalence of dental caries was $14.3 \%$. The results showed that the prevalence of dental caries and dental trauma was similar, and that both caused the same amount of damage to dental health in the target population.[35]

Cristiano Susin assess the prevalence and severity of TDI (traumatic dental injuries)and its association with socio-demographics and physical characteristics in the anterior permanent teeth of 12- year-old Brazilian schoolchildren. He showed a high prevalence of TDI in 12-year-old Brazilian schoolchildren. Sociodemographic data and school achievement were associated with TDI.[3]

Bugra Ozen investigated the prevalence and etiology of dental trauma in children aged 2-15 in the Eastern Black Sea Region of Turkey. Trauma was found to occur most frequently in girls aged 8 years and boys aged 10 years. The majority of injured teeth were the permanent maxillary central incisors in both primary and permanent dentitions. Single-tooth injury was predominant in all age groups. Children with an overjet greater than $3 \mathrm{~mm}$ accounted for a greater percentage of dental injuries than those with an overjet less than $3 \mathrm{~mm}$. Overjet was not found to have a significant effect on the number of teeth involved in a traumatic dental injury. The most common cause of dental trauma was 'falls'with the frequent type of injury being enameldentin crown fracture without pulpal exposure in permanent dentition and lateral luxation in primary dentition. He also concluded that families and healthcare systems need to provide safe and appropriate firstaid treatment for traumatic dental injuries, with followup treatment by dental-health providers.[36]

Skaare and Jacobsen ] reported that $48 \%$ of dental injuries occurred at school, and half of leisure time injuries occurred during children play in Oslo, Norway. Sports and accidents represented only $8 \%$ of the total number of injuries and injuries done by violence representing $8 \%$ of the injuries. [37]Sarheed et al. studied the prevalence of traumatized permanent teeth among visual and hearing impaired children in Saudi Arabia and found that incisor teeth involved in all the dental injures. Trauma was noted in 9\% of visual impaired and $11.4 \%$ of hearing impaired children.

Gender difference were apparent in the hearing impaired children with male having higher levels of traumatized teeth.[38] Andreasen reported that $13 \%$ to $39 \%$ of all dental injuries are sports related. He reported among 434 cases, that $82 \%$ of the teeth traumatized were maxillary incisors, $64 \%$ central incisors, $15 \%$ lateral incisors, and $3 \%$ canines .Men and boys sustained 2 to 3times more injuries when compared to women and girls, and with most patients between the ages of 8 and 15 years. In 434 cases, only a slight difference existed in the percentage of dental trauma incurred by each sex of 434 cases of trauma.[6]

The etiological factors varied according to the age group studied, and this association can be explained by age- related activities and the characteristics of motor coordination development as the majority of TDI cases resulted from falls in age group 9-12 years. With the increase of age, traffic crashes became the main etiologic agent, as reported elsewhere.

\section{Conclusion}

Overall traumatised permanent incisors were found to occur fairly frequently with males having experienced significantly more TDIs than females. The prevalence of TDIs was $12,2 \%$.Falls was the most common reason. In boys and girls samples where collected within school time.The results suggested that boys were more susceptible to traumatic injury of anterior teeth, and the highest prevalence of dental trauma was determined in the 8 years age.Higher than boys in the 11years age girls group type score 3(Coronal fracture without pulp exposure). The result show that boys with 9-10 years age were more susceptible to traumatic injury score 4 type (Fracture from enamel and dentine involve expose pulp area). More prospective studies from representative populations are required to understand the complexities of dental trauma to develop appropriate strategies to reduce the increasing frequency of dental trauma. 


\section{Acknowledgements}

The authors gratefully acknowledged all the dentists different dental private clinics in Israel participants for taking part in this study.

\section{References}

[1]. Marcenes W, al Beiruti N, Tayfour D, Issa S. Epidemiology of traumatic injuries to the permanent incisors of 9-12-year-old schoolchildren in Damascus, Syria.

Endod Dent Traumatol 1999; 15(3):117-123.

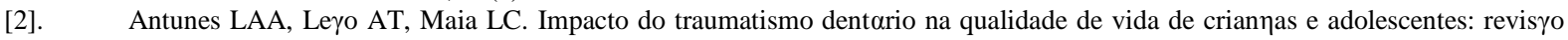
crvtica e instrumentos de medida. Cien Saude Colet 2012; 17(12):3417-3424

[3]. Damt-Teixeira N, Alves LS, Susin C, Maltz M. Traumatic dental injury among 12-year-old South Brazilian scholchildren: prevalence, severity, and risk indicators. Dent Traumatol 2013; 29(1):52-58.

[4]. Cortes MI, Marcenes W, Sheiham A. Impact of traumatic injuries to their permanent teeth on the oral health related quality of life in 2-14 year old children. Community Dentistry and Oral Epidemiol 2002; 30: 193-198.

[5]. Renall DN. Sports dentistry and dental traumatology. Dental traumatol 2002; 18: 231-236.

[6]. Andreasen JO, Andreasen FM. Essentials of Traumatic injuries to the teeth. 2nd ed. Copenhangen, Denmark Munksgaard and Mosby, 2000; 9: 154.

[7]. Flores MT, Andreasen JO, Backland LK, Ferdin B, Gutman JL, Oikarinen K et al. Traumatic dental injuries (Part 2 of the series) Dental Traumatology 2002; 18: 287-298.

[8]. Andreasen, J.O. (1970a). Etiology and pathogenesis of traumatic dental injuries. A clinical study of 1298 cases. Scand J Dent Res; $18: 329-42$

[9]. Flores MT, Andreasen JO, Batland LK. Faiglin B, Gutman SL, Oikarinen K et al. Guidelines for the evaluation and management of traumatic dental injuries (part 3 of the series). Dental; Traumatrology 2001; 17: 97-102.

[10]. Onetto J, Flores M, Garbarino M. Dental trauma in children and adolescents in Valparaiso, Chile. Endod Dent Traumatol. 1994; 10(5):223-7.

[11]. .Sakare AB, Jacobsen I. Dental injuries in Norwegians aged 7-18 years. Dental tranmatology 2002; 19: 67-71

[12]. Díaz JA, Bustos L, Brandt AC, Fernández BE. Dental injuries among children and adolescents aged 1- 15 years attending to public hospital in Temuco, Chile. Dent Traumatol 2010;26:254- 61.

[13]. Patel MC, Sujan SG. The prevalence of traumatic dental injuries to permanent anterior teeth and its relation with predisposing risk factors among 8- 13 years school children of Vadodara city: An epidemiological study. J Indian Soc Pedod Prev Dent 2012;30:151- 7

[14]. Hasan AA, Qudeimat MA, Andersson L. Prevalence of traumatic dental injuries in preschool children in Kuwait - A screening study. Dent Traumatol 2010;26:346- 50

[15]. Lihong, G.E., Chen, J., Zhao, Y., Xia, B., Kimura M. . Analysis of Traumatic Injury in 886 Permanent Anterior Teeth. J Hard Tissue Biol2005;14 (2): 53-54.

[16]. Naidoo S, Sheiham A, Tsakos G. Traumatic dental injuries of permanent incisors in 11- to 13- year- old South African schoolchildren. Dent Traumatol 2009;25:224- 8 .

[17]. Yassen GH, Chin JR, Al- Rawi BA, Mohammedsharif AG, Alsoufy SS, Hassan LA, et al. Traumatic injuries of permanent teeth among 6- to 12- year- old Iraqi children: A 4- year retrospective study. J Dent Child (Chic) 2013;80:3-8

[18]. Kovacs M, Pacurar M, Petcu B, Bukhari C. Prevalence of traumatic dental injuries in children who attended two dental clinics in Targu Mures between 2003 and 2011. Oral Health Dent Manag 2012;11:116- 24

[19]. Dua R, Sharma S. Prevalence, causes, and correlates of traumatic dental injuries among seven- to- twelve- year- old school children in Dera Bassi. Contemp Clin Dent 2012;3:38- 41.

[20]. Altun C, Ozen B, Esenlik E, Guven G, Gürbüz T, Acikel C, et al. Traumatic injuries to permanent teeth in Turkish children, Ankara. Dent Traumatol 2009;25:309-13

[21]. David J, Åstrøm AN, Wang NJ. Wang Factors associated with traumatic dental injuries among 12-year-old schoolchildren in South India. Dent Traumatol 2009;25:500-5

[22]. Glendor U. Epidemiology of traumatic dental injuries - a 12 year review of the literature. Dent Traumatol 2008;24:603-11.

[23]. Lam R, Abbott P, Lloyd C, Lloyd C, Kruger E, Tennant M. Dental trauma in an Australian rural centre. Dent Traumatol 2008;24:663-70

[24]. .Eyuboglu O, Yilmaz Y, Zehir C and Sahin H. A 6-year investigation into types of dental trauma treated in a paediatric dentistry clinic in Eastern Anatolia Region, Turkey. Dent Traumatol 2009;25:110-4

[25]. Naidoo S, Sheiham A, Tsakos G. Traumatic dental injuries of permanent incisors in 11- to 13- year- old South African schoolchildren. Dent Traumatol 2009;25:224- 8

[26]. .Navabazam A, Farahani SS. Prevalence of traumatic injuries to maxillary permanent teeth in 9- to 14-yearold school children in Yazd, Iran. Dent Traumatol 2010;26:154-7.

[27]. Faus-Damiá M, Alegre-Domingo T, Faus-Matoses I, Faus-Matoses V, Faus-Llácer VJ. Traumatic dental injuries among schoolchildren in Valencia, Spain. Med Oral Patol Oral Cir Bucal 2011;16:e292-5.

[28]. .Saroglu I, Sonmez H. The prevalence of traumatic injuries treated in the pedodontic clinic of Ankara University, Turkey, during 18 months. Dent Traumatol 2002;18:299-303

[29]. Gassner R, Tuli T, Hachl O, et al. Craniomaxillofacial trauma in children: a review of 3,385 cases with 6,060 injuries in 10 years. J Oral Maxillofac Surg 2004; 62: 339-407.

[30]. Gutmann JL, Gutmann MSE. Cause, incidence, and prevention of trauma to teeth. Dent Clin North Am 1995; 39:1.

[31]. Kumar A, Bansal V, Veeresha KL, Sogi GM. Prevalence of traumatic dental injuries among 12- to 15-year-old schoolchildren in Ambala district, Haryana, India. Oral Health Prev Dent 2011;9:301-5.

[32]. Bendo CB, Paiva SM, Oliveira AC, Goursand D, Torres CS, Pordeus IA, et al. Prevalence and associated factors of traumatic dental injuries in Brazilian schoolchildren. J Public Health Dent 2010;70:313-8.

[33]. Jorge KO, Oliveira Filho PM, Ferreira EF, Oliveira AC, Vale MP, Zarzar PM. Prevalence and association of dental injuries with socioeconomic conditions and alcohol/drug use in adolescents between 15 and 19 years of age. Dent Traumatol 2012;28:136-41. 
[34]. Livny A, Sgan-Cohen HD, Junadi S, Marcenes W. Traumatic dental injuries and related factors among sixth grade schoolchildren in four Palestinian towns. Dent Traumatol 2010;26:422-6.

[35]. Ferrari PHP, Zaragoza RA, Ferreira LE, Bombana AC; Horizontal root fractures a case report. Dent Traumatol 2006; 22: 215 225.

[36]. . Ozen B, Cakmak T, Altun C, Bagis B, Senel FC, Baltacioglu E, Koskan O; Prevalence of dental trauma among children age 215 years in the Eastern Black Sea Region of Turkey. J Int Dent Med Res, 2010; 3(3):126-132.

[37]. Skaare AB, Jacobsen I; Etiological factors related to dental injuries in Norwegians aged 7-18 years. Dent Traumatol, 2003; 19:304-308

[38]. Sarheed AM, Bedi R, Hunt NP; Traumatized permanent teeth in $11-16$-year-old Saudi Arabian children with a sensory impairment attending special school. Dent Traumatol, 2003; 19:123-125. 